\title{
Development Situation and Prospect of Chinese Industrial Robots
}

\author{
Haichao Gao, Ruipeng Guo and Pengcheng Li \\ Department of Machinery and Electronics, Henan \\ Vocational College of Chemical Technology, Zhengzhou \\ 450042, China
}

\begin{abstract}
With the rising of Chinese labor costs, industrial robots as a new type of labor force, is quietly changing employment pattern of China's manufacturing industry. This article first introduced the current development of industrial robots at home and abroad, summed up the current situation of China's industrial robots in a number of important issues, the research status of domestic industrial robot were reviewed, and the prospects for the development of China's industrial robots in the future.
\end{abstract}

Keywords-Industrial robots, Intelligent control, Industrialization.

\section{INTRODUCTION}

Industrial robot is reprogrammable multifunctional manipulator which used for transporting materials, parts, tools, etc., or the special unit by calling the different programs to accomplish various tasks[1]. Industrial robot is a branch of robotics, which represents the highest achievement of mechatronics. In industrialized countries, the rapid development of industrial robot through half a century, the increasingly mature technology, in the automotive industry, electronic industry, machine tool industry, foundry industry, aerospace, chemical industry, food industry, textile industry, plastics industry, logistics industry and many other areas has been widely used. Industrial robot as an important advanced manufacturing equipment, has become an important symbol to measure a country's level of manufacturing and technological level.

With the rising of Chinese labor costs, industrial robots as a new type of labor force, is quietly changing the manufacturing employment patterns. At present, Chinese artificially production mode, will gradually replaced by the robot. The robot will become the dominant mode. the latter rate and high labor cost advantage is increasingly concerned by industrial enterprises. The latter with high labor rate and low cost advantage is more and more getting the attention of industrial enterprises. Widespread adoption of industrial robots, which not only can improve the quantity and quality of products, but also can protect the personal safety of the workers, improve working environment, reduce labor intensity, improve labor productivity, save raw materials consumption and reduce production cost, to promote the rise of China's manufacturing industry is of great significance[2].

\section{DEVELOPMENT SitUATION OF INDUSTRIAL RobOTS}

\section{A. Development Status of Foreign Industrial Robots}

Since 1962, the United States launched the world's first industrial robot, robot got rapid development in the industrial developed countries. Although it started late compared with Europe and America, but in less than a decade surpassed the United States in the manufacture and application, known as the Robot Kingdom, caused widespread attention. In 1967, Japan imported the first robot from the United States, began robot commercial production in the second year, opened the prelude of the development of Japan's robots[3]. Today, Japan has become the world's largest production and possession country of industrial robots.

In the 1980s, the world's rapid development in industrial production technology of high degree of automation and integration, also led further development in industrial robots, and industrial robots had played a key role in the development of industrial economy for the whole world in this period. Currently, the industrial robots in the world either from the technical level or from the number of assembled are mature, dominant concentrated in a few industrialized countries, Japan, the US, represented, has become a standard device, widely used in the industry. Countries around the world have had a number of influential and well-known industrial robot enterprises, including: ABB, FANUC, YASKAWA, KUKA, CLOOS, Adept Technology, COMAU, IGM and other companies. These companies have become the pillar enterprises in their country[4-6].

\section{B. Current Development of Domestic Industrial Robots}

The research of industrial robots in China began in the 1970s, due to the restriction of economic system and other factors at the time, the development was slow, the level of research and application was relatively low. In 1985, with the beginning of large-scale application and popularization of industrial robots in industrialized countries, our country started from the 7th five-year key science and technology plan, included in the development plan of industrial robots $[7,8]$.

After 30 years of development, China's industrial robot industry has formed a relatively complete industrial base and has played an important role in the field of manufacturing, emergency rescue, field exploration, resource development, national defense and other fields . But compared to the huge market demand, there is still obviously insufficient. Although in recent years China's 
industrial robot industry has developed rapidly, but the domestic industrial robot industry started late, overall, China's industrial robot industry in its infancy, the smaller overall size; affected by the stage of industrial development, leading enterprises are located in the $\mathrm{R} \& \mathrm{D}$ focus of the Northeast areas; technical inputs increasing year by year, but the core technology has not yet industrialization; strong manpower substitution demand, the market application prospect is broad[9]. China's industrial robots in technology and engineering application level comparing with the international level, there is a certain gap.

First, the overall development level is low, the core technology controlled by others. Although China has basically mastered the technologies of industrial robots, such as the design and manufacturing technology of robot manipulator, the hardware and software design of control system, kinematics and trajectory planning techniques, but the scale of production of industrial robots is still small, narrow application areas, the reliability and accuracy of product less than foreign products, only equivalent to the foreign level in the mid-1990s, cost performance of product is low. Due to the long-term dependence on foreign imports of high-performance servo motors, precision reducer, servo drives, controllers and other key core components, the cost of China's industrial robots is high[10]. Therefore, the localization of the core components of the robot is imminent. Once these key components achieving localization, the average cost can be reduced by $30 \%$, while the single robot manufacturing cost is reduced by at least $20 \%$.

Secondly, dominated by foreign brands, the influence of independent brand is weak. China has a number of enterprises and research institutes engaged in the development of industrial robots, although has entered the initial stage of industrialization, but has not formed a large scale, lack of brand awareness of the market, low market share[11]. ABB, FANUC, YASKAWA, KUKA, Adept Technology, COMAU and other brands of industrial robots occupy 90 percent of China's application market. At present, China's new industrial robots depend on foreign imports more than 70 percent. Japanese FANUC which only one company share in the Chinese market reached 23\%. In 2012, the sales growth of Japan's FANUC and Germany's KUKA was more than $100 \%$ in China. In 2012, the domestic brand robot sales only 1112 units, and the sole proprietorship and joint venture brand sales reached 25790 units, the market share of $4 \%$ and $96 \%$ respectively. Among them, ABB, KUKA, FANUC, YASKAWA four industrial robot giant sales reached 14470 units in 2012, accounting for $53.8 \%$ of the proportion[12]. In contrast, foreign robots in China's market share, domestic independent brands are in disadvantage position. Moreover, foreign enterprises use the whole machine low price dumping and improve the maintenance cost of spare parts strategies, continue to suppress domestic brands, further occupation of the Chinese market[13].

\section{RESEARCH STATUS OF CHINESE INDUSTRIAL ROBOTS}

At present, the Chinese industrial robots in the design, manufacture or in regard to the application, compared with the developed countries have a large gap. Domestic industrial robots basically use foreign brands as a template to imitation, improve supplemented, relying on the experience and trial, lack of in-depth theoretical analysis and optimization calculation in the design process, resulting in a large difference in the properties between domestic robots and foreign brands. To enhance the performance of the robot, at the design stage should adopt modern advanced analysis and design methods, the major components and overall structure of the robot should be analyzed and optimized[14].

Industrial robot research on kinematics calibration, motion planning and control has mature control scheme[15]. Because of the industrial robot control is nonlinear and multi variable, while the manufacturing industry also put new demands on the performance of the robot, robot control method is still the focus of research, the industrial robot technology turns to the direction of intelligent, heavy load, high precision, high speed and network development. Combining position, torque, power, vision and other information feedback, compliance control, hybrid control, visual servo control and other methods have been conducted a lot of research to meet the needs of high speed, high precision and intelligence operation. The use of network technology, not only simplifies the system structure of the industrial robots, but also realizes coordinated operation[16].

On the industrial robot research, many domestic universities and research institutes, such as Harbin Institute of Technology, Shenyang Automation Research Institute of Academy, Chinese Academy of Sciences Institute of automation research, Tsinghua University, Beijing University of Aeronautics and Astronautics, Tianjin University, Shanghai Jiao Tong University, a lot of work has been carried out, have achieved abundant performances in aspects as structure, drive and control, established the technical foundation for the development of the domestic robot industry[17-20]. With the domestic demand for industrial robots more and more urgent, Shenyang SIASUN Robot \& Automation Co., Ltd., Harbin Institute of Technology Boshi Precision Measure \& Control Co., Ltd., GSK CNC Equipment Co., Ltd., Chery Automobile Co., Ltd. and other enterprises get rapid development in the aspect of industrial robot industry[21-23].

\section{PRospect OF THE DEVElopment OF CHINESE INDUSTRIAL ROBOTS}

By the end of 2013, the Ministry of Industry and Information Technology issued "Ministry of Industry and Information Technology guidance on promoting the development of the industrial robot industry", required by 2020, China's industrial robot industry and enterprise technology innovation ability and international competition ability enhanced obviously, the high-end product market share increase to more than $45 \%$, ten thousand employees use the robot number more than 100 units, basically meet the needs of national economic, social development and national defense construction. By 2020, "Guidance" putting forward, forming relatively complete system of industrial 
robots industry, cultivating 3-5 leading enterprises with the international competitiveness and 8-10 supporting industry clusters, conquering the technology of the servo motor, precision motor reducer, servo driver, end effector, sensors and other key parts, and forming the productivity[24]. China clearly increased the cultivation of local industrial robots and the support.

The future development of Chinese robot market has huge potential. According to the International Federation of Robotics (IFR) statistics, China market scale would reach 28,000 units in 2014, expected to keep pace with the Japan. By 2015, China market scale will reach 34,000 units, 3,000 units more than Japan, having the world's largest demand of industrial robots[25].

In recent years, more and more extensive application of industrial robots, the signs that the time has come for industrial automation. China's industrial robot industry is in an unprecedented opportunity, on the one hand, national policy support, for the support of national policies, will promote and contribute to the development and growth of domestic industrial robot industry; on the other hand, China's manufacturing industry transformation and upgrading, transformation and upgrading of manufacturing industry will promote the development of industrial automation equipment. China has the huge domestic market demand. For the development prospects of Chinese industrial robots, judging by the present situation of research and development of Chinese industrial robot and its development tendency, the industrial robot industry in China is full of difficulties and challenges, but also full of hope.

\section{CONCLUSIONS}

The robot industry will be the emerging large-scale high technology industry, following the automobile, computer industry. With the rapidly rising labor costs and the adjustment and upgrade of manufacturing industry structure, China industrial robot industry has entered in a golden period of development. China is on the magnificent transformation towards the world's largest Robot Kingdom. To shorten the gap of our industrial robot research and application with foreign countries, our country must make use of our own advantages on the development road of industrialization. On the road of development, our country must learn from the successful experience of foreign development of industrial robotics industry, coupled with the support of national policy, the development of industrial robots in China although full of difficulties and challenges, but the future is bright.

\section{REFERENCES}

[1] Zhenbiao Wu, Zhengjia Wang. Industrial Robots (Second Edition). Wuhan: Huazhong University of Science and Technology Press, 2006.

[2] Guang Ma, Guiying Shen. The present situation and developing trend of industrial robot. Modular Machine Tool \& Automatic Manufacturing Technique, 3, pp. 48-51, 2002.

[3] Chuanbi Wang. Development of industrial robots in Japan and its economic benefits. The Journal of Quantitative \& Technical Economics, 9, pp. 67-71, 1985.
[4] Xinbo Chen. Japan's robot industry status and development trend. Mechatronics, 6(6), pp. 14-15, 2000.

[5] Jinyou Wang, Discussion on the development of robot industry in China. Robot Technique and Application, 6, pp. 2-4, 2003.

[6] Yingfei Sun, Aihua Luo, Development Research on China's Industrial Robot. Science Technology and Engineering, 20(12), pp. 29122918,3031, 2012.

[7] Ruifeng Li, Development Strategy for China Industrial Robot. Aeronautical Manufacturing Technology, 9, pp. 32-37, 2010.

[8] Yujian Li, Ming Chao, Present and future of national industrial robots. Manufacturing Automation, 12, pp. 106-108, 2010.

[9] Industrial robots may encounter the outbreak period but backward in technical level. Machine Tool \& Hydraulics, 41(10), pp. 111-111, 2013.

[10] Huashan Feng, Xiansheng Qin \& Runxiao Wang. Industrial robots development trends in the field of aerospace manufacturing. Aeronautical Manufacturing Technology, 19, pp. 32-37, 2013.

[11] Jie Zhao. Development and Challenge of Chinese Industrial Robot. Aeronautical Manufacturing Technology, 12, pp. 26-29, 2012.

[12] Zhigang Gao. China Industrial Economy Dynamic, 4, pp. 23-24, 2014.

[13] Wenting Liu, Hong Gao. Chinese industrial robot applications and challenges. Outlook Weekly, 7, pp. 38-39, 2014.

[14] Yisheng Guan, Xiu Deng, Huaizhu Li, Zhenneng Yin, Wenqiang Wu \& Li Jiang, Structural Analysis and Optimization of Industrial Robot. Journal of South China University of Technology(Natural Science Edition), 9, pp. 126-131, 2013.

[15] Min Tan, De Xu, Zengguang Hou, Shuo Wang \& Zhiqiang Cao. Advanced Robot Control. Beijing: Higher Education Press, 2007.

[16] Min Tan, Shuo Wang, Research Progress on Robotics. Acta Automatica Sinica, 39(7), pp. 963-972, 2013.

[17] Wenzeng Zhang, Qiang Chen, Dong Du, Zhenguo Sun \& Guoxian Zhang, 3-D vision-based trajectory tracking of welding robots. Journal of Tsinghua University(Science and Technology), 47(8), pp. 1270-1273, 2007.

[18] Tianran Wang \& Daokui Qu, Open System Architecture for Control system for Industrial Robot. Robot, 24(3), pp. 256-261, 2002.

[19] Changjie Liu, Chengchao Xie \& Shenghua Ye, Study on real-time calibration and compensation of the coordinate measurement system for industry robot. Journal of Optoelectronics•laser, 22(1), pp. 86-90, 2011.

[20] Jiawang Li, Xuyang Wang \& Tong Ge, Adaptive Robust Control for an Active Heave Compensation System. Journal of Shanghai Jiaotong university, 1, pp. 17-24, 2013.

[21] Zhenyu Liu, Zhongsheng Li, Tao Zhang \& Xue Zhao, Research of Palletizing Technology Based on Industrial Robot of Machine Vision. Modular Machine Tool \& Automatic Manufacturing Technique, 4, pp. 9-14,18, 2014.

[22] Qizhong Chen, Yanbiao Zou, Tie Zhang \& Qingsong Zhou, Development of Off-line Programming System for Spray Robot. Machine Tool \& Hydraulics, 41(11), pp. 122-124,101, 2013.

[23] Jinxue Cao. Localisation Development of Off-line Programming Software of Spot-welding Robot and Its Application. Computer Applications and Software, 28(12), pp. 99-101, 2011.

[24] Information on http://www.miit.gov.cn

[25] China Becoming the Robot Kingdom and Exceeding Japan as the World's First. Foundry Panorama, 2, pp. 28-28, 2014. 